Military Technical College Kobry Elkobbah, Cairo, Egypt.

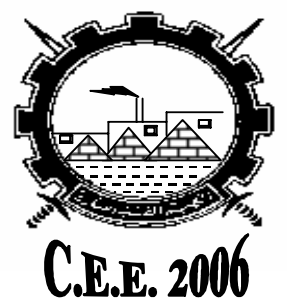

$3^{\text {rd }}$ International Conference

On

Chemical \& Environmental

Engineering

\title{
EFFECT OF TRANSITION METAL INCORPORATION IN MCM-41 ON THE PHOTOCATALYTIC DEGRADATION OF CHLOROPHENOL. PART I CHROMIUM
}

\author{
Aboul-Gheit A. K. ", Emara M. M. " , Ali R. A. ${ }^{* *}$ and \\ El-Moselhy M. M.
}

\section{ABSTRACT}

MCM-41 modification with Cr cation was carried out by direct synthesis using of the surfactant templating process and the impregnation method. The produced molecular sieves were characterized by XRD, FTIR spectroscopy and $\mathrm{N}_{2}$ adsorption-desorption. All prepared materials acquired a typical MCM-41 structure. The prepared samples were tested in the photocatalytic degradation of 3-chlorophenol in aqueous medium. The reactants and products were analyzed using high performance liquid chromatography (HPLC) and ion chromatography (IC). The data obtained indicate that the structure modifications of MCM-41 affected not only the activity of MCM-41 for the disappearance of chlorophenol but also for the degradation intermediates.

\section{KEYWORDS}

Mesoporous; catalyst synthesis; MCM-41 Photolysis; 3-Chlorophenol; UV irradiation; HPLC; IC

\footnotetext{
* Egyptian Petroleum Research Institute, Cairo, Egypt.

Faculty of science, Alazhar university.
} 


\section{INTRODUCTION}

The photo-catalytic degradation of organic contaminants requires using a suitable catalyst, either homogenous or heterogeneous to achieve the target in an economic solution. The Vast majority of catalysts are composed of $\mathrm{TiO}_{2}$ with varying conditions to get the optimum catalyst dosage and suitable conditions for complete removal of pollutants $[1,2]$. Recently, the zeolite family has attracted the attention of many authors to be used in photo-degradation processes by virtue of their higher activities and larger surface areas [2-5]. Zeolites of different types have been used in several photo-chemical processes and in particular for the removal of organic pollutants. It has been found that, not only surface area, but also pore volume significantly affects the photo degradation process of many hydrocarbons [5]. MCM-41 is a mesoporous molecular sieve possessing well ordered pores of different size ranges making them suitable to be used for a wide range of applications in the field of heterogeneous catalysis. Active sites can be generated via chemical modification, i.e. by introducing a cation into the silica matrix [6-8]. Incorporation of transition metal centers in the silicate framework can lead to improvement in its use in catalysis via creating new active sites which assist the enhancing of degradation of organic pollutants [8-10]. Hence, transition metal cations such as $\mathrm{Al}, \mathrm{Ti}, \mathrm{Cr}$, Fe and $\mathrm{Mn}$ [11-15] have been incorporated into MCM-41. The obtained materials have shown the remarkable catalytic activity for partial oxidation of hydrocarbons under mild conditions [16-20]. Transition metals ( $\mathrm{Cr}, \mathrm{V}, \mathrm{Fe})$ based titania loaded MCM-41 materials have tested for degrading organics in visible light. The chromium substituted MCM- 41 was found to serve as the best support for titania to achieve the highest degradation rates of formic acid and 2,4,6-trichlorophenol [14]. Fe-MCM-41 has been used for oxidation of sulfur dioxide [16]. Aluminum incorporated MCM-41, which possess moderate Lewis acidity associated with the presence of $\mathrm{Al}$ in the framework position, has been claimed to be an effective hydrothermal and isomerization catalyst [9-13]. For AlMCM-41, the hydroxyl groups of the framework have been assumed to serve as electro acceptors with production of hydrogen atoms. The channel/cage system of these zeolites can also be modified with suitable cations via ion exchange techniques. Moreover, successful ion exchange in the mesoporous silica has been achieved in solution. The ion exchange site of a zeolite is usually carried out by substituting trivalent Al for silicon atoms. Al-MCM-41 exhibits ion exchange capacities for $\mathrm{Na}, \mathrm{K}$ and $\mathrm{Y}$.

Several methods are used for introducing metal cations into zeolite framework [21]. The method of catalyst synthesis has been reported to influence the position, dispersion, surface area and concentration of the incorporated metal [22-24]. Generally, ion exchange and impregnation are the most frequently applied catalyst preparation method incorporating the metal outside the framework of the zeolite. However, the in situ synthesis is comparatively a new method for sin which the metal cation in incorporated in the framework [25]. This method depends mainly on the addition of the transition metal cations during synthesis thereby; the metal cation can occupy a certain location in zeolite framework via replacing Al by desired cation, and hence leading to the formation of new active sites that play important role in the photodegradation reactions. 
Chlorinated hydrocarbons are widely used in plastics, pesticides and wood preservations. Of particular interest, small quantities of the herbicides 2,4dichlorophenol (2,4-DCP) and the fungicide pentachlorophenol (PCP) [26] are typically found in drinking and ground waters. They are highly chemically stable in these media and their greater solubility in fatty materials compared to water, and can lead to significant toxicity in the bioaccumulation in animals and humans [27]. Photominerlization of these two pollutants by direct photolysis in natural sunlight can take months (half-life ca. 6-14 days) [28]. Thus, the active interest in the last decades in developing faster degradative processes could easily be applied to the treatment of waste waters [29].

In the present work, the in situ synthesis of MCM- 41 molecular sieve achieved the incorporation of $5 \% \mathrm{Cr}^{3+}$ cation in the MCM-41 framework in the position of $\mathrm{Al}^{3+}$. In the catalyst prepared via impregnation method, the MCM-41 was impregnated with a solution containing the requite quantity of $\mathrm{Cr}$ as a precursor (chromium acetate) to attain $5 \mathrm{wt} \%$ in the finished catalyst. Catalysts have been examined for the photocatalytic degradation of 3-chlorophenol in aqueous solution. The removal of chlorophenol and the production of the photodegradtion intermediates were traced using mainly HPLC and IC chromatography.

\section{EXPERIMENTAL}

\subsection{Catalyst synthesis}

Synthesis of the MCM-41 mesoporous molecular sieve was carried out using a modification of the method described in references [23, 24]. The reagents used were sodium silicate (Aldrich), n-cetyl-triethylammonium bromide (Aldrich) and aluminum sulfate (Merck). A gel mix was prepared and introduced in $200 \mathrm{ml}$ autoclave. The synthesis was carried out in an oven at $105{ }^{\circ} \mathrm{C}$ for 6 days. Subsequently the autoclave is quenched and the mesoporous material was filtered and washed with distilled water then dried at $100{ }^{\circ} \mathrm{C}$ overnight and calcined at $550{ }^{\circ} \mathrm{C}$ for $4 \mathrm{~h}$. Modification of MCM-41 was carried out using the impregnation and in-situ synthesis methods.

\subsubsection{Impregnation method}

The Cr-MCM-41 catalyst was prepared via impregnation of Na-MCM-41 using $5 \%$ $\mathrm{Cr}^{3+}$ acetate. The impregnation was carried out at $25^{\circ} \mathrm{C}$ for $24 \mathrm{~h}$. the catalyst was filtered, dried and calcined as above $550{ }^{\circ} \mathrm{C}$. This catalyst was designated $\mathrm{Cr}(\mathrm{Al}) \mathrm{MCM}-41$

\subsubsection{In-situ method}

The in-situ synthesis technique was carried out by directly adding $5 \%$ aqueous $\mathrm{Cr}^{3+}$ acetate into the gel followed by the synthesis of MCM- 41 in a similar procedure as mentioned above for preparing the parent Na-MCM-41. The Cr-modified catalyst synthesized via in-situ method was denoted as Cr-MCM-41. 


\subsection{Catalyst characterization}

The Na-MCM-41, Cr(Al)MCM-41 and Cr-MCM-41 mesoporous molecular sieve catalysts were evaluated using XRD, FTIR spectroscopy and nitrogen adsorption. The phase purity and structure of MCM-41 were determined by X-ray powder diffraction using Philips diffractometer PW 3710 and $\mathrm{Cu}$ ka radiation. The samples were measured in the $2 \theta$ range of $10-50^{\circ}$ at $40 \mathrm{kv}, 30 \mathrm{~mA}$, and a scanning rate of $2^{\circ}$ in $2 \theta \mathrm{min}^{-1}$. FTIR analysis of the prepared samples was carried out on Bruker (Vector 22 ), singl beam spectrometer with a reslution of $2 \mathrm{~cm}^{-1}$.

\subsection{Chlorophenol photocatalytic degradtion.}

The catalytic activities of the prepared catalysts were tested for the photodegradation of 3-chlorophenol in a $200 \mathrm{ml}$ cylindrical silica glass reactor using $6 \mathrm{~W}$ Hg lamp (254 nm) was immersed in the photoreactor. The total radiant flux amounted to $\left(20 \mathrm{~m} \mathrm{~W} \mathrm{~cm}^{-2}\right.$ ) was measured using an UV radiometer (Digital, UVx 36). In another version of experiments, $\mathrm{H}_{2} \mathrm{O}_{2}$ was used as oxidant at a concentration of $3 \times 10^{-}$ ${ }^{5} \mathrm{M}$ at $25^{\circ} \mathrm{C}$.

\section{RESULTS AND DISCUSSION}

\section{1. physico-chemical properties}

\subsubsection{X-ray powder diffraction}

The X-ray diffraction pattern of Na-MCM-41 (Fig 1) is similar to that reported in literature, indicating that the synthesized mesoporous molecular sieve material has an ordered hexagonal cylidrical shape channel system. for $\mathrm{Cr}(\mathrm{Al}) \mathrm{MCM}-41$ and Cr-MCM-41 (Fig $1 \mathrm{a}-\mathrm{b}$ ) the difraction patterns were similar to that of the parent MCM-41 (Fig 1). Non of the prepared samples show separate oxidic phase indicating well incorporation of the metal inside the MCM-41 channels. 


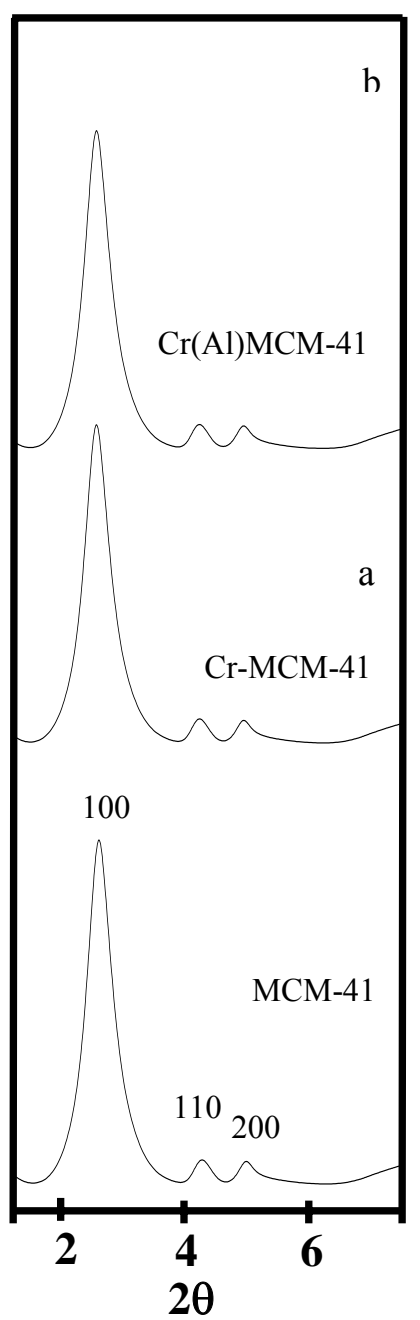

Fig. 1: XRD of MCM-41 in comparison with $\mathrm{Cr}-\mathrm{MCM}-41$ prepared by tow different methods

a) $\mathrm{Cr}(\mathrm{Al})-\mathrm{MCM}-41$

b) $\mathrm{Cr}-\mathrm{MCM}-41$

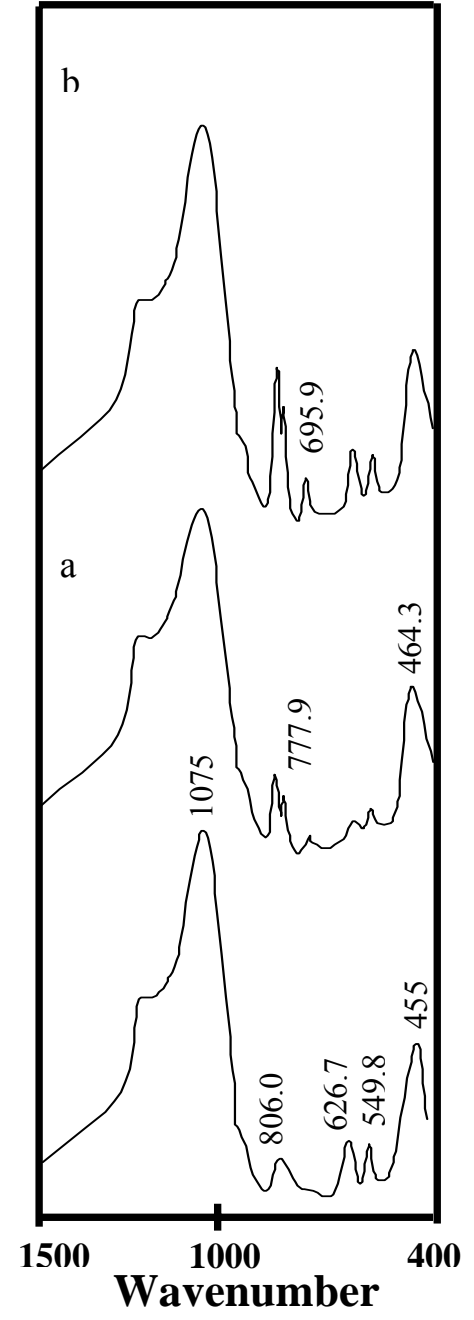

Fig. 2: FTIR spectra of MCM-41 in comparison with $\mathrm{Cr}-\mathrm{MCM}-41$ prepared by tow different methods

a) $\operatorname{Cr}(\mathrm{Al})-\mathrm{MCM}-41$

b) $\mathrm{Cr}-\mathrm{MCM}-41$ 


\subsubsection{FTIR spectroscopy}

Figure 2 shows the FTIR spectra for MCM-41, $\mathrm{Cr}(\mathrm{Al}) \mathrm{MCM}-41$ and $\mathrm{Cr}-\mathrm{MCM}$ 41 samples, calcined at $550{ }^{\circ} \mathrm{C}$ in the $1500-400 \mathrm{~cm}^{-1}$ range. The spectrum of MCM-41 shows the vibrational bands of hexagonal silica at 1075,806 and $455 \mathrm{~cm}^{-1}$ that are identical to amorphous silica together with, two bands at 549 and $626 \mathrm{~cm}^{-1}$. It can be seen that the band at $455 \mathrm{~cm}^{-1}$ corresponding to bending vibration of Si-O does not encounter any change following metal ion incorporation. Similarly, the band at 549 $\mathrm{cm}^{-1}$, characteristic for presence of five membered rings in the structure of zeolite [24-30] does not indicate any change. The tow bands absorbing at 450 and $550 \mathrm{~cm}^{-1}$ are typical for framework vibrational characteristic of ZSM-5, in addition to, the band at $626 \mathrm{~cm}^{-1}$, characteristics of Al-O-belonging to alternating $\mathrm{SiO}_{4}$ and $\mathrm{AlO}_{4}$ tetrahedra [31-34].

The spectra for $\mathrm{Cr}(\mathrm{Al}) \mathrm{MCM}-41$ and $\mathrm{Cr}-\mathrm{MCM}-41$ (Fig 2 a-b) show distinct bands at $695 \mathrm{~cm}^{-1}$ and $777 \mathrm{~cm}^{-1}$ which are absent in the spectra of the forgoing samples. These bands can be correlated with these of the Cr-oxide species [35]. This view is confirmed by the significant increase in intensity of the 695 and $777 \mathrm{~cm}^{-1}$ bands in the Cr-MCM-41 samples. In addition, Cr-MCM-41 does not show any change in the 549 and $626 \mathrm{~cm}^{-1}$ bands, confirming that Al species are in framework positions. These bands can be, on the other hand, due to $\mathrm{Cr}$-silicate which used to show strong additional shoulder at 1030, 800 and $540 \mathrm{~cm}^{-1}$ and a weak additional band at $640 \mathrm{~cm}^{-}$ ${ }^{1}$, that can be attributed to $\mathrm{Cr}$ in framework structure [32]. As a further confirmation, an enhancement in intensity of the $806 \mathrm{~cm}^{-1}$ band is shown in $\mathrm{Cr}(\mathrm{Al}) \mathrm{MCM}-41$ and $\mathrm{Cr}$ MCM-41 samples.

\subsubsection{Surface area measurements}

The cation modified MCM-41 samples calcined at $300{ }^{\circ} \mathrm{C}$ for $3 \mathrm{~h}$, under a reduced pressure of $10^{-5}$ torr, show either type IV or type II isotherms with an enhanced uptake in the low pressure range $\left(0.01-0.1 \mathrm{P} / \mathrm{P}^{\circ}\right)$. The obtained adsorptiondesorption isotherms are depicted in Figure 3, Surface properties such as BET surface area and total pore volume were calculated for MCM-41 modified cations using the standard BET method $[36,37]$ based on the adsorption data obtained in the relative pressure range $0.04-0.25$. The total pore volume was assessed from the amount adsorbed at $\mathrm{P} / \mathrm{P}^{\circ}=0.99$ [38]. The micro pore volume $\mathrm{V}^{\text {mic }}$, external surface area $S^{\text {ext }}$ and primary meso-pore volume $V p$ were obtained using $V_{\text {l-t }}$ plot method [39] are given in (Table 1). Figure 3 shows hysteresis loops of different shapes and areas depending on the nature of cation used. For the two $\mathrm{Cr}$-modified MCM-41 samples, the closing point occurs at $\mathrm{P} / \mathrm{P}^{\circ}$ values of $0.31-0.58$ except for $\mathrm{MCM}-41$ which indicate a closing point at $\mathrm{P} / \mathrm{P}^{\circ}=0.95$. Generaly, it can be clearly that the surface areas of the Cr-icorporated MCM-41 are lower when compared to parent pure MCM41. The average pore diamters change upon incorporation of transition metal.

The $\mathrm{V}_{\mathrm{l}-\mathrm{t}}$ curves of the samples are shown in Figure 4 which have been drawn using the reference $t$ values [34] depending on the value of the BET C-constant given in Table 1. The obtained $V_{\text {l-t }}$ plot of the parent MCM-41 (Fig 4-a) shows an upward inflection onset at $t=21.24 \AA\left(P / P^{\circ}=0.35\right)$ and continuing up to $t \approx 44.96 \AA$ ( $P / P^{\circ}=$ $0.85)$ where it becomes nearly linear, indicating domination of wide pores associated with capillary condensation. The plot obtained for Cr-MCM-41 sample (Fig 4-b) 
exhibites a downward inflection compared to the MCM-41 curve (Fig 4-a), indicating partial blocking of wider pores of the zeolite on replacing of $\mathrm{Al}^{3+}$ by $\mathrm{Cr}^{3+}$ during preparation. This is evident by the downward deviation in the Cr-MCM-41 sample (Fig 4-b) that started at $\mathrm{t}=1.912 \AA\left(\mathrm{P} / \mathrm{P}^{\circ}=0.025\right)$ and continues with increasing slope up till $t=6.018 \AA\left(P / P^{\circ}=0.55\right)$. However, the $\mathrm{Cr}(\mathrm{Al}) \mathrm{MCM}-41$ sample (Fig 4-C), exhibit a downward deviation in the range $5.31-9.77 \AA$ is observed with a higher tendency to horizontality. Comparing the data depicted in Table 1 it is clear that the micro pore volume $\left(\mathrm{V}^{\mathrm{mic}}\right)$ and meso-pore volume $\left(\mathrm{V}^{\mathrm{meso}}\right)$ of unloaded $\mathrm{MCM}-41$ are higher than those in $\mathrm{Cr}-\mathrm{MCM}-41$ and $\mathrm{Cr}(\mathrm{Al}) \mathrm{MCM}-41$. The calculated value of mesopores in $\mathrm{Cr}(\mathrm{Al}) \mathrm{MCM}-41$ and $\mathrm{Cr}-\mathrm{MCM}-41$ are respectively, 0.53 and $0.36 \mathrm{~cm}^{3} \mathrm{~g}^{-1}$ indicating that $\mathrm{Cr}$ is mainly incorporated in the meso-pores.

Table 1. Some surface characteristics of modified MCM-41. The samples were pretreated at $300{ }^{\circ} \mathrm{C}$ under a reduced pressure of $10^{-5}$ torr.

\begin{tabular}{|c|c|c|c|c|c|c|}
\hline $\mathbf{C}$ & $\mathbf{r}$ & $\begin{array}{c}\mathbf{V}_{\mathbf{B J H}} \\
\left(\mathbf{c m}^{3} / \mathbf{g}\right)\end{array}$ & $\mathbf{V}_{\mathbf{p}}{ }^{\text {meso }}$ & $\mathbf{V}_{\mathbf{p}}{ }^{\text {mic }}$ & $\begin{array}{c}\mathbf{S}_{\mathbf{B E T}} \\
\mathbf{m}^{2} / \mathbf{g}\end{array}$ & Sample \\
\hline 39 & 28 & 0.98 & 0.65 & 0.33 & 880 & MCM-41 \\
\hline 6 & 34 & 0.61 & 0.36 & 0.25 & 376 & Cr-MCM-41 \\
\hline 13 & 32 & 0.68 & 0.53 & 0.15 & 533 & Cr(Al)MCM-41 \\
\hline
\end{tabular}

Note: $\mathrm{S}_{\mathrm{BET}}$ : $\mathrm{BET}$ surface area; $\mathrm{V}^{\text {mic }}$; micropore volume; $\mathrm{V}^{\text {meso }}$ meso pore volume $\mathrm{V}_{\mathrm{BJH}}$ : total pore volume.

Table 2. Kinetics of Photo-catalytic degradation reaction of 3-Chlorophenol

\begin{tabular}{|c|c|c|}
\hline $\begin{array}{c}\text { Rate constants } \\
\left(\text { min }^{-1}\right)\end{array}$ & $\begin{array}{c}\text { Time of complete } \\
\text { degradation (min.) }\end{array}$ & sample \\
\hline 0.043 & 250 & $\mathrm{MCM}-41$ \\
\hline 0.096 & 150 & $\mathrm{Cr}-\mathrm{MCM}-41$ \\
\hline 0.102 & 150 & $\mathrm{Cr}(\mathrm{Al}) \mathrm{MCM}-41$ \\
\hline 0.046 & 150 & $\mathrm{H}_{2} \mathrm{O}_{2}$ \\
\hline 0.040 & 120 & $\mathrm{MCM}-41 / \mathrm{H}_{2} \mathrm{O}_{2}$ \\
\hline 0.045 & 100 & $\mathrm{Cr}-\mathrm{MCM}-41 / \mathrm{H}_{2} \mathrm{O}_{2}$ \\
\hline 0.0622 & 40 & $\mathrm{Cr}(\mathrm{Al}) \mathrm{MCM}-41 / \mathrm{H}_{2} \mathrm{O}_{2}$ \\
\hline
\end{tabular}




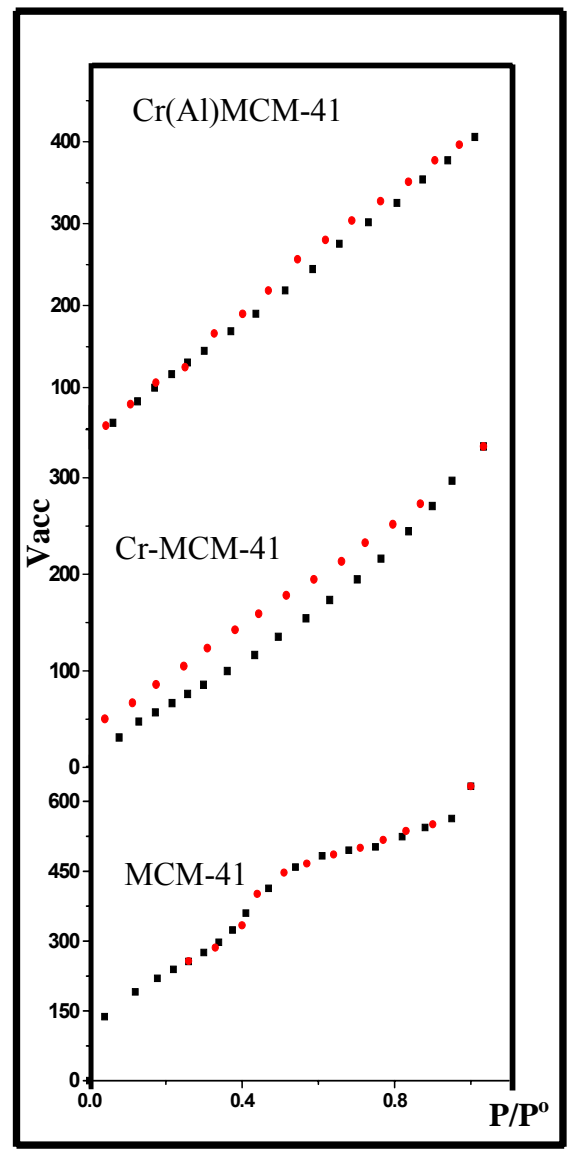

Fig. 3: Nitrogen adsorptiondesorption isotherm of MCM41 in comparison with that of Cr-MCM-41 prepared with two different methods.

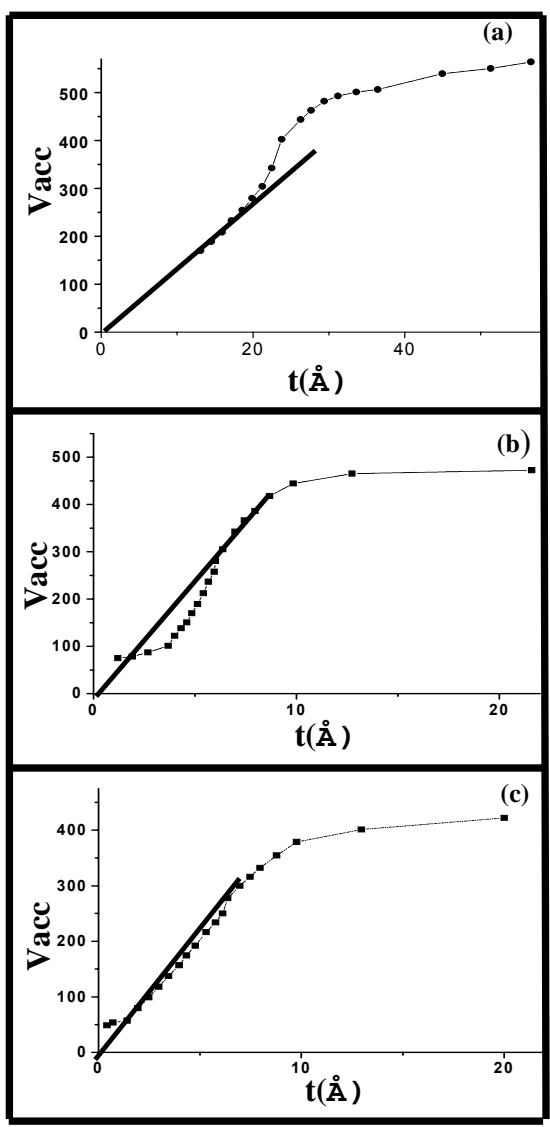

Fig. 4: $\mathrm{V}_{\mathrm{I}-\mathrm{t}}$ plots of $\mathrm{MCM}-41$ and cations modified MCM-41 prepared by two different methods; either in situ or ion exchange
(a) MCM-41
(b) $\mathrm{Cr}-\mathrm{MCM}-41$
(c) $\mathrm{Cr}(\mathrm{Al}) \mathrm{MCM}-41$ 


\subsection{Direct photolysis of 3-CP with UV irradiation}

Direct photolysis is claimed to be efficiently applied for the degradtion of chlorinated hydrocarbons, trihalomethanes [41], chlorinated compounds [42,43], nitro-aromatic compounds [44] and certain pesticides [45].

In the present work, the first series of experiments, include direct photolysis of 3-CP in water at a concentration of $300 \mathrm{ppm}$ in a photoreactor, via using $254 \mathrm{~nm}$ UV irradiation. HPLC analysis shows that 3-CP completely disappears after $225 \mathrm{~min}$ of irradiation (Fig. 5a). The only aromatic intermediate identified was phenol.

Photolysis of 3-CP has been significantly accelerated on addition of $\mathrm{H}_{2} \mathrm{O}_{2}$ where its complete disappearance is attained after $120 \mathrm{~min}$ of irradiation (Fig 5b). Further more, during photolysis several aliphatic compounds including carboxylic acids (acetic and formic) and hydorxylated carboxylic acids have been identified in addition to phenol. These products exhibit low UV absorption not allowing their complete identification except for formic and acetic acids. This finding is substantiated by the results of Guyon et. al. [46].

Applying the 3-CP/ $\mathrm{H}_{2} \mathrm{O}_{2}$ (Fig 5-b) system it is found that the destruction capability of acetic acid to formic acid is significantly enhanced. The maximum concentration of acetic acid relatively significantly decreases to reach $\sim 90 \mathrm{ppm}$ during irradiation period $50-90 \mathrm{~min}$, beyond which formic acid jumps to as high as $145 \mathrm{ppm}$ that persists till $125 \mathrm{~min}$ then declines with a further increase of irradiation time till disappears at $200 \mathrm{~min}$. These data may show that the mechanism can pass principally through the following steps:

$$
3-\mathrm{CP} \longrightarrow \text { Acetic acid } \longrightarrow \text { Formic acid } \longrightarrow \mathrm{CO}_{2}+\mathrm{H}_{2} \mathrm{O}
$$

whereas the mechanism of photolysis in absence of $\mathrm{H}_{2} \mathrm{O}_{2}$, a low concentration of phenol remains in the photolysis product exhibiting a somewhat milder $\mathrm{C}-\mathrm{Cl}$ bond fission activity.

\subsection{Heterogeneous photocatalytic degradation of 3-CP using MCM-41 and $\mathrm{Cr}$ - modified MCM-41}

Figs 6-8 show the photo degradation activity of MCM-41 and its $\mathrm{Cr}^{3+}$ modified versions using the impregnation method [ $\mathrm{Cr}(\mathrm{Al}) \mathrm{MCM}-41]$ and the in situ method [Cr$\mathrm{MCM}-41]$. Figure 6 a-b illustrates the degradation course of 3-CP, where formation and subsequent degradation of intermediates take place using MCM-41 in absence as well as in presence of $\mathrm{H}_{2} \mathrm{O}_{2}$. Cesaro et al. [46] and Guittonneau et al. [47] have detected the formation of several intermediates during the degradation of chlorophenols on aqueous slurry of $\mathrm{TiO}_{2}$, these intermediates have been completely degraded further to $\mathrm{CO}_{2}$ and $\mathrm{HCl}$. However, in the present work, formic and/or acetic acids are the main intermediates formed during this reaction. The results obtained show that chlorophenol has been degraded principally to acetic using $\mathrm{Cr}(\mathrm{Al}) \mathrm{MCM}$ 41 catlyst in absence of $\mathrm{H}_{2} \mathrm{O}_{2}$, but to both acetic and formic acids in presence of $\mathrm{H}_{2} \mathrm{O}_{2}$. This supports the finding that pyrolysis behaves similarly in presence and absence of $\mathrm{H}_{2} \mathrm{O}_{2}$. 
It should be pointed out that modification of MCM-41 with $\mathrm{Cr}^{3+}$ has a significant effect on the catalytic activities, Fig 6a shows that CP completely disappears after $190 \mathrm{~min}$ irradiation using the MCM-41 catalyst, whereas it disappearance at 100 and $135 \mathrm{~min}$ using the $\mathrm{Cr}(\mathrm{Al}) \mathrm{MCM}-41$ and $\mathrm{Cr}-\mathrm{MCM}-41$ catalyst (Figs $7 \mathrm{a}$ and $8 \mathrm{a}$ ) respectively. However, using MCM-41, only formic acid has been formed as intermediate; it forms since beginning of irradiation and increases to a maximum of $175 \mathrm{ppm}$ at $105 \mathrm{~min}$ then declines with further irradiation to completely disappears at $180 \mathrm{~min}$. Even though some phenol has been formed via dechlorination of 3-CP, where a maximum of $25 \mathrm{ppm}$ of phenol is reached at $30 \mathrm{~min}$ irradiation, then slowly decrease till totally disappears at 135 min on using Cr-MCM-41 catalyst (Fig 8a).

The decrease in $\mathrm{pH}$ value of the solution results due to dechlorination of 3-CP and formation of $\mathrm{HCl}$ which increases as a function of irradiation time. Correlating the effect of $\mathrm{H}_{2} \mathrm{O}_{2}$ addition to the solution containing the Cr-MCM-41 catalyst, is evident via comparing the data in Figs $8 \mathrm{a}$ and $8 \mathrm{~b}$. Evidently, 3-CP completely disappears at $180 \mathrm{~min}$ on the Cr-MCM-41/ $\mathrm{H}_{2} \mathrm{O}_{2}$ catalyst, compared to $135 \mathrm{~min}$ in the absence of $\mathrm{H}_{2} \mathrm{O}_{2}$. Also, 


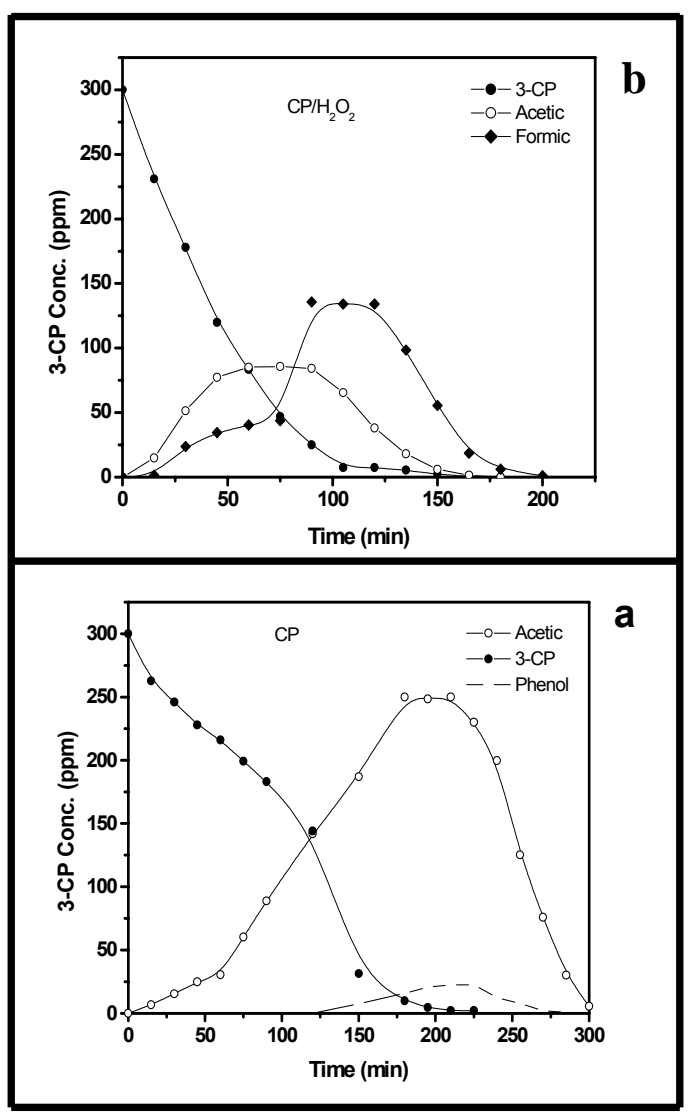

Fig. 5: Photodegradation of 3-CP and concomitant appearance of intermediate products formed during irradiation.

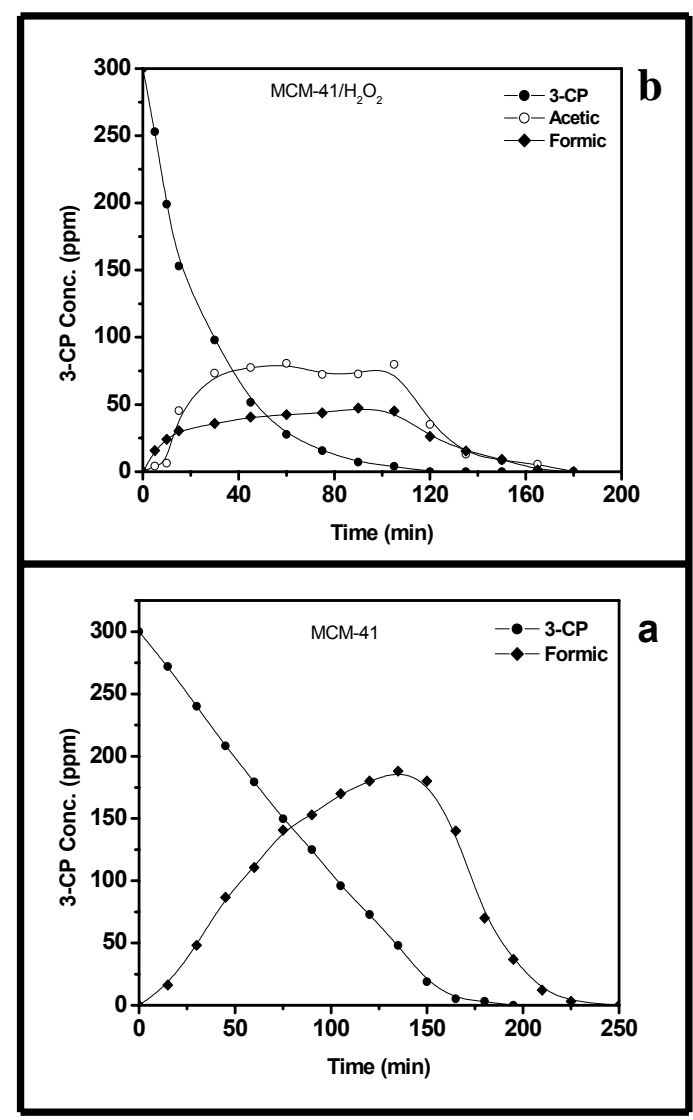

Fig. 6: Photodegradation of 3-CP and concomitant appearance of intermediate products formed during irradiation. 


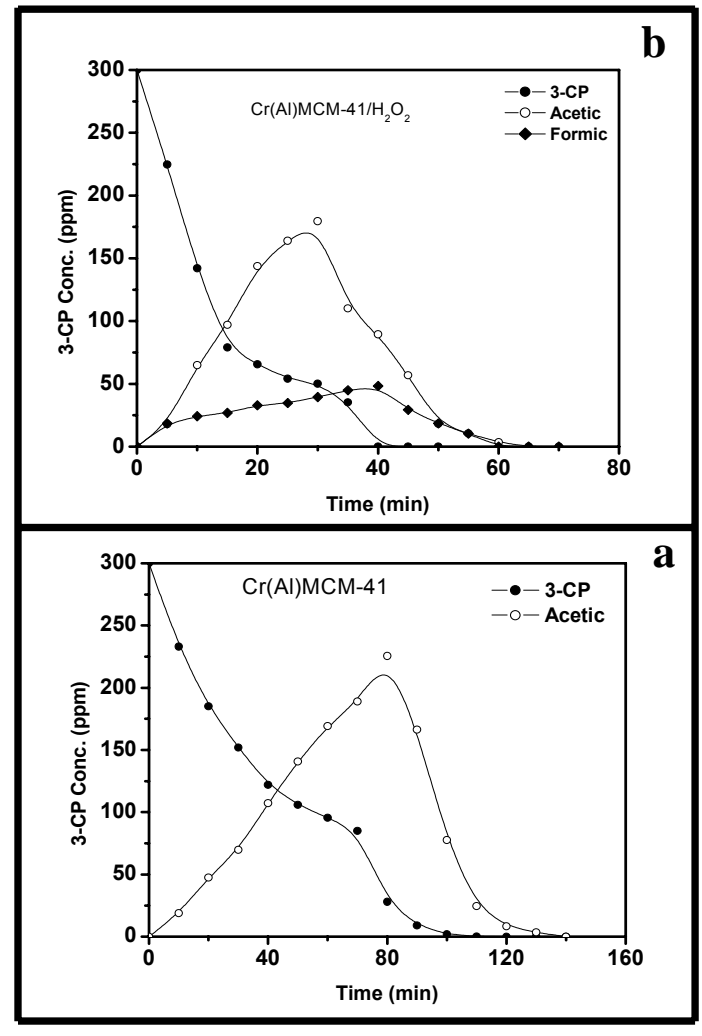

Fig. 7: Photodegradation of 3-CP and concomitant appearance of intermediate products formed during irradiation.

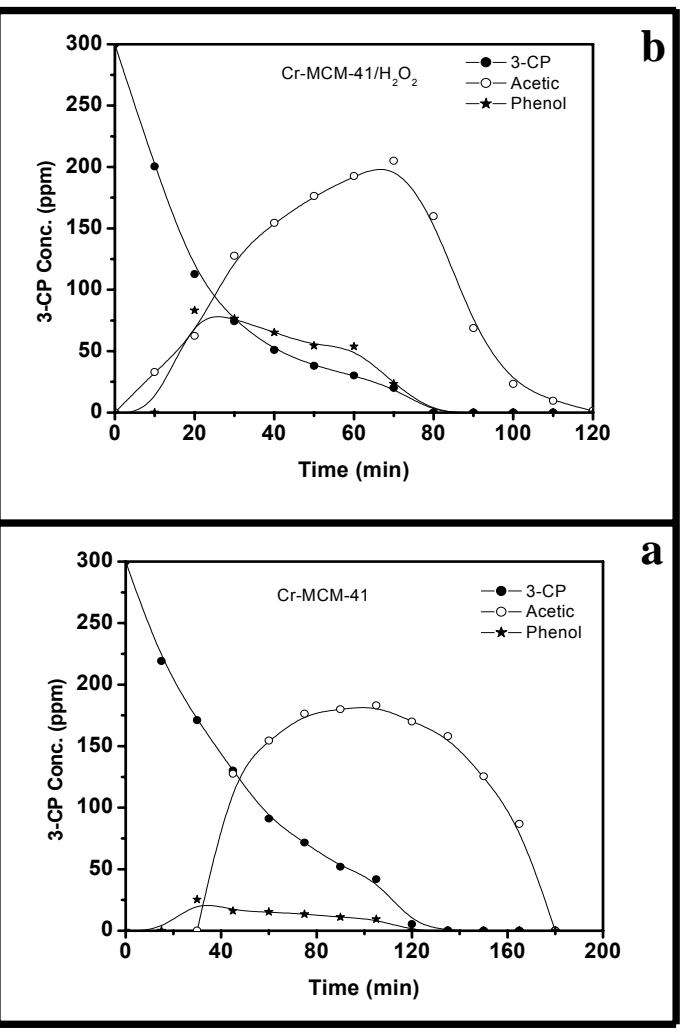

Fig. 8: Photodegradation of 3-CP and concomitant appearance of intermediate products formed during irradiation. 
$\mathrm{H}_{2} \mathrm{O}_{2}$ affects the faster disappearance of acetic acid at 120 min compared to 160 min in absence of $\mathrm{H}_{2} \mathrm{O}_{2}$ using $\mathrm{Cr}-\mathrm{MCM}-41$ catalyst. However, phenol is higher (75 ppm at 30 min irradiation) than in absence of $\mathrm{H}_{2} \mathrm{O}_{2}$.

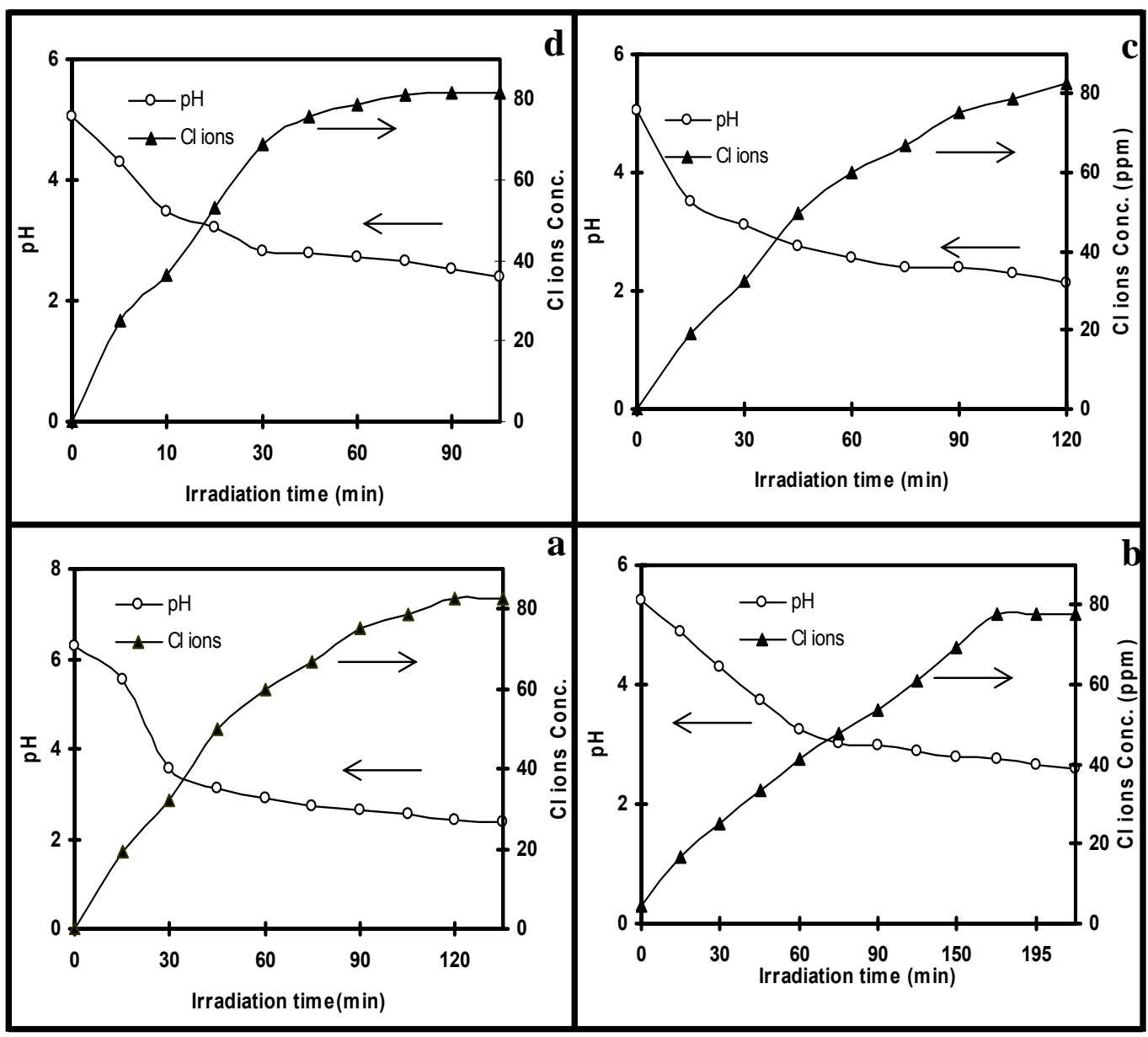

Fig. 9: Variation of chloride ions and pH during the photodegradation process as a function of irradiation time.
a) $\mathrm{CP}$
b) $\mathrm{CP} / \mathrm{H}_{2} \mathrm{O}_{2}$
c) $\mathrm{MCM}-41$
d) $\mathrm{MCM}-41 / \mathrm{H}_{2} \mathrm{O}_{2}$ 


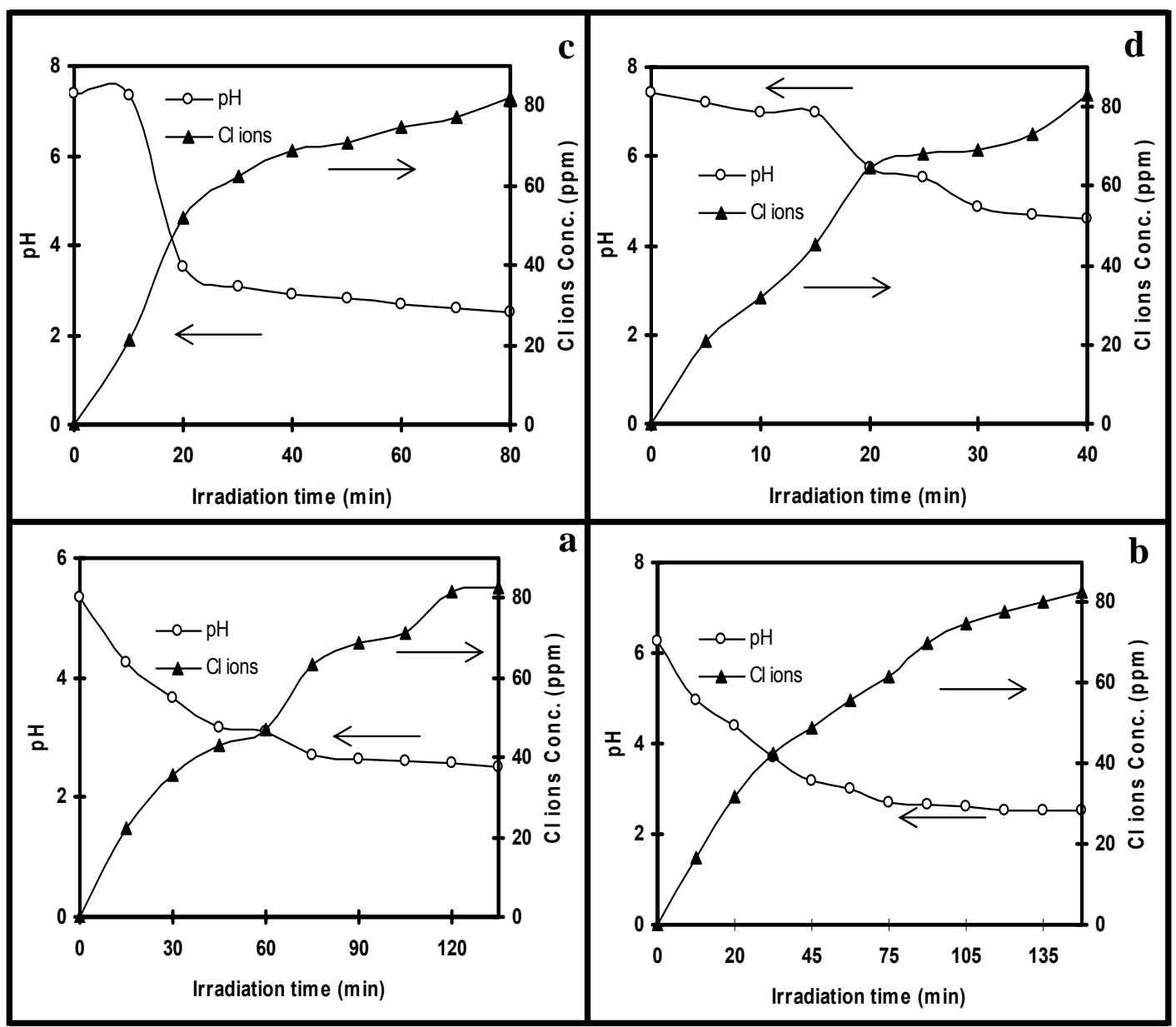

Fig. 10: Variation of chloride ions and $\mathrm{pH}$ during the photo-degradation process as a function of irradiation time.
a) $\mathrm{Cr}-\mathrm{MCM}-41$
b) $\mathrm{Cr}(\mathrm{Al}) \mathrm{MCM}-41$
c) $\mathrm{Cr}-\mathrm{MCM}-41 / \mathrm{H}_{2} \mathrm{O}_{2}$
d) $\mathrm{Cr}(\mathrm{Al}) \mathrm{MCM}-41 / \mathrm{H}_{2} \mathrm{O}_{2}$ 
In all cases, after illumination with UV light the photodegradation reaction was found to follow pseudo first order kinetics. The data were fitted to the corresponding logarithmic expression to get an apparent rate constant in $\min ^{-1}$ (Fig 11). The rate constant is not regarded as fully interpretable since we know that a complete kinetic treatment includes substrate concentration dependence from zero to first order and other variable dependence on light intensity [18]. Thus, k simply serve to compare relative activities of the catalysts under study (Table 2 ).
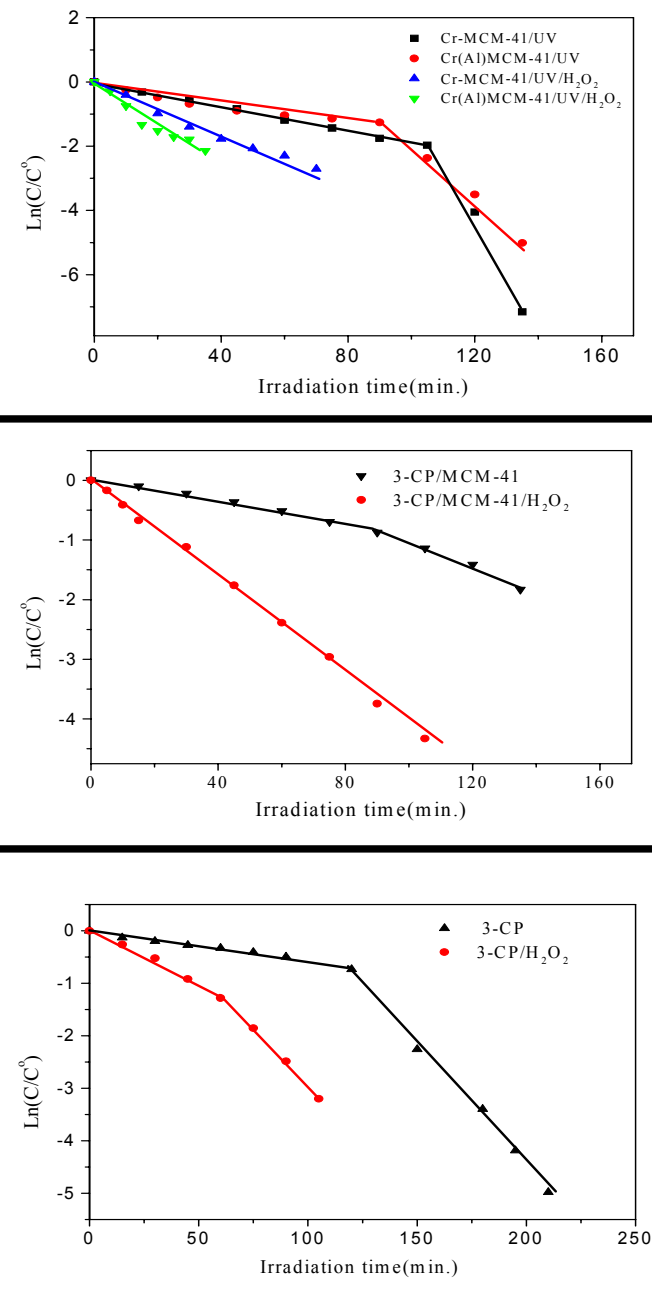

Fig. 11: $\operatorname{Ln}(\mathrm{C} / \mathrm{Co})$ against irradiation time of 3-CP with MCM-41 and $\mathrm{H}_{2} \mathrm{O}_{2}$ 


\section{CONCLUSION}

This research underlines the unique properties of MCM-41 and its Cr-modified version as a photocatalyst for the degradation of Chlorophenol. The XRD and FTIR data suggest the well dispersion of $\mathrm{Cr}$ species along with the pure phase of MCM-41. The Cr-modified MCM-41 via impregnation method shows the highest photocatalytic degradation of 3-CP.

\section{ACKNOWLEDGMENTS}

This work was supported and carried out in the laboratories of Science Center for Detection and Remediation of Environmental Hazards (SCDREH) in Al-Azhar University (SCDREH@yahoo.com).

\section{REFERENCES}

[1] Dinwang Chen. Ajay K. Ray Appl. Catl. B: Environ. 23 (1999) 143- 157.

[2] V. Durgakumari. M. Subrahmanyam, K. V. Subba Rao, A. Ratnamala, M. Noorjahan, KeiiChi Tanaka. Appl. Catal. A: General 234 (2002) 155-165.

[3] Y. Xu, C. H. Langford, J. Phys. Chem. 99 (1995) 11501.

[4] P. G. Smirniotis. L. Davydov, Catal. Rev. Sci. Eng. 41 (1999) 43.

[5] V. I. Parvulescu, S. Coman, P. Palade, D. Macovei, C. M. Teodorescu, G. Filoti, R. Molina, G. Poncelet, F. E. Wagner, Appl. Surf. Sci. 141 (1999) 164.

[6] A. Corma, Chem. Rev. 97 (1997)2373.

[7] S. Biz, M. L. Occelli, Catal. Rev.-Sci. Eng. 40 (1998)329.

[8] A. Sayari, Chem. Mater. 8 (1996) 1840

[9] O. N. Le, R. T. Thomas, US patent 5, 232, 580 (1993)

[10] A. Corma, M. T. Navarro, J. P. Pariente, J. Chem. Soc., Chem. Commun. (1994) 147.

[11] H. kosslick, G. Lischke, G. Walther. W. Stroek, A. Martin

[12] F. Rey, G. Shankere, T. Mashmeyer, J. M. Thomas, R. G. Bell, Top. Cata. 3 (1996) 121.

[13] J. M. Thomas, Faraday Discuss. 100 (1995) C9.

[14] L. Davydov, E. P. Reddy, P. France, P. G. Smirniotis, J. Cata. 203 157.

[15] J. Q. Wang, S. Uma, K. J. Klabunde, Appl. Cata. B. 48 (2004) 151.

[16] A. Wingen, N. Anastasievic, A. Hollnagel, D. Werner, F. Schuth, J. Catal. 193 (2000) 248.

[17] B. Notari. Adv. Cata. 41 (1996) 253.

[18] M. anpo, M. Che, Adv. Catal. 44 (1999) 119.

[19] Shan Wang, Tao Dou, Yuping Li, Ying Zhang, Xiaofeng Li, Zichun Yan, J Of solid state chemistry 177 (2004) 4800-4850.

[20] M. Hartmann, C. Bischof, Z. Luan, L. Kevan, Micropor. Mesopor. Mater. 4445 (2001) 385.

[21] L. Mercadante, G. Neri, C. Milone, A. Donato, S. Galvagno, J. Mol. Catal. A: Chem. 105 (1996) 93.

[22] M. Consonni, D. Jokic, D. Yu. Murzin, R. Touroude, J. Catal. 188 (1999) 165.

[23] T. J. Hall, J.-E. Halder, G. J. Hutchings, R. L. Jenkins, P. Johnston, P. Mcmorn, P. B. Wells, R. P. K. Wells, Top. Catal. 11/12 (2000).

[24] H. H. schmidtke and D. Garthoff, J. Am. Chem. Soc. 89, 1317 (1967) 
[25] E. D. Garbowski and C. Mirodatos, J. phys. Chem. 86, 97 (1982)

[26] P Boule, C. Guyon, A. Tissot, J. Lemaire, in: Photochemistry of Environmental aquatic System, American Chemical society Meeting, Miami Beach, FL, April 1985, pp. 10-26

[27] B. J. Nebel, Environmental Science: the Way the World Works, Prentice-Hall, Englewood Cliffs, NJ, 1981, pp. 308-363.

[28] H. M. Huang, R. E. Hodson, R. F. Lee, in: Photochemistry of Environmental aquatic System, American Chemical society Meeting, Miami Beach, FL, April 1985, pp. 27-43

[29] D. M. Blake, Biblography of Work on the Heterogenous Photocatalytic Removal of Hazardous compounds from Water and Air, National renewable Energy Laoboratory, Report No. NREL/TP-430-22197, 1997 and NREL/TP-430-26797, 1999.

[30] S. Coluccia, A. J. Tench, R. L. segall, J. chem. Soc. Faraday Trans. 1, 75 (1978)

[31] A. Zecchina, F. S. stone, J. chem. Soc. Faraday Trans. 1, 74, 2278 (1978)

[32] R. B. singer, T. B. Mccord and R. N. clark, J. Geophy. Res. 84 No. 814, 8415 (1979)

[33] C. R. Bamford, phys. Chem. Glasses 1, 159, 165 (1960).

[34] J. S. T. Mambrin, H. O. Pastore, C. U. Davanzo, E. J. S. Vichi, O. Nakumura, H. Vargas, Chem. Mater. 5, 166 (1993)

[35] D. J. Lensveld, J. G. Mesu, A. J. Van Dillen and K. P. de jong, Micropor. Mesopor. Mater., 44-45, 401 (2001).

[36] D. J. Lensveld, J. G. Mesu, A. J. Van Dillen and K. P. de jong and ibid., Stud. Surf. Sci. Catal., 143, 647 (2002).

[37] A. C. Voegtlin, A. Matijasic, J. Patarin, C. Sauerland, Y. Grillet and L. Huve, Micropor. Mater., 10, 137 (1997).

[38] K. Abburi. Journal of Hazardous Materials B105, 143-156 (2003).

[39] H. Al-Ekabi, P. de Mayo, J. Phys. Chem. p. 4075-4082, 90 (1986)

[40] Kresge, C. T.; Leonowicz, M. E.; Roth, W. J.; Vartuli, J. C.; Beck, J. S. Nature 1992, 359, 710.

[41] D. Zaho, J. Feng, Q. huo, N. Melosh, G. H. Fredrickson, B. F. Chmelka and G. D. Stucky. Science, Vol. 279 (1998).

[42] S. Coluccia, A. J. Tench, R. L. segall, J. chem. Soc. Faraday Trans. 1, 75 (1978)

[43] A. Zecchina, F. S. stone, J. chem. Soc. Faraday Trans. 1, 74, 2278 (1978).

[44] Beck, J.S; Vartuli, J.C.; Roth,W.J.; Leonowicz, M.E.; Kresge, C.T.; Schmitt, K.D.; Chu, C.T.W.; Olson, D.H.; Sheppard, E.W.J.Am. Chem. Soc.1992,114, 10834.

[45] I.Nicole, J.De Laat, M.Dore, J.P. Duguet, H.Suty, Environ. Technol. 12 (1991) 21.

[46] D. Cesareo, A. Di Domenico, S. Marchini, L. passerine, M. L. Tosato, in: E. Pelizzett, N. Serpone (Eds.), Homogeneous and heterogeneous Photocatalysis, Reidel, Dordrecht, 1986, p. 593.

[47] S. Guittonneau, J. De Laat, M. Dore, J. P. Duguet, C. Bonel, Rev. Sci. Eau. 1 (1988) 35.

[48] D. Hessler, C. F. Schenk, F. H. Frimmel, in: Proceedings of the IWSA Workshop on Advanced Oxidation processes, Coral Gables, FL, AWWA, Denver, 1992.

[49] D. Peterson, D. Watson, W Winterlin, Bull. Environ. Contam. Toxicol. 44 (1990) 744.

[50] C. Guyon, P. Boule, J. Lemaire, Tetrahedron Lett, 23 (1982) 1581.

[51] P. Boule, J. Lemaire, Chemosphere 11 (1982) 1179. 